evidence evisceration is associated with too low a ratio of suture length (SL) to wound length (WL). The risk of evisceration (and ventral hernia) rises increasingly rapidly as the ratio SL: WL falls from $2: 1$ to $1: 1$ (or lower). On theoretical grounds closure with a simple continuous stitch using a stitch interval of $1 \mathrm{~cm}$ and a ratio SL: WL between $4: 1$ and $6: 1$ gives conditions in the wound so that the effect of $30^{\circ}$ ", wound lengthening leads to a rise in tension of less than $2^{\circ}$ between the sutures and the tissues. Further, I have shown clinically that if the sutures are unabsorbable and monofilament, then sepsis in the wound or deep in the abdomen causes minimal risk of evisceration or ventral hernia.

It is not difficult and very little time is required to include with the operation notes the ratio SL: WL used in each fascial layer. Some surgeons fear that a large amount of non-absorbable sutures in the wound will lead to foreign body complications. I have a paper ready for publication showing that in the repair of ventral (incisional) hernia, having excised all scar tissue, closure of the fascial layers anatomically, using loop nylon, metric 3, at a ratio SL : WL of as much as $25: 1$ leads to sound wound healing without foreign body reaction and without recurrence of ventral hernia.

It now remains for other surgeons to apply measurement to the other methods of fascial closure in the interrupted stitch pattern, the continuous mattress stitch, and the Smead Jones (massive suture) stitch techniques. As a result of this scientific check on the art of wound closure our profession should be able to ensure that virtually every wound includes a margin of safety adequate to withstand all predictable postoperative stresses, including that of deep abdominal sepsis.

T P N JENKINS

Guildford

' Jenkins, T P N, British fournal of Surgery, 1976, 63,

SIR,-Burst abdominal wounds are preventable. They are the result of poor surgical technique. I was pleased that your leading article (26 February, p 534) referred to the paper by Mr Terry Jenkins, ${ }^{1}$ which should be read by all practitioners of surgery. He has now brought science to the art he has been practising and teaching for so many yearsnamely, taking big bites and suturing loosely.

I was fortunate to be his registrar and have used his technique of abdominal closure for the past eight years, during which time only one of my wounds has dehisced. This occurred in 1971, nine hours after resection of a carcinoma of the duodenojejunal flexure through an upper midline incision. Exploration of the wound showed that the nylon knot had undone-a technical fault of my knotting, not of the suturing technique.

During the past three years I have periodically measured the length of wounds and of the nylon used and, like Mr Jenkins, have found that the nylon length has a mean of four times that of the incision length. Further evidence of the validity of this concept comes from three burst wounds I have repaired recently for other people. In each case the nylon had torn out of the tissue, and in two cases the length of nylon was less than the length of the wound.

Other advantages of suturing wounds according to the Jenkins's principles are that they appear more comfortable for the patient; pus can drain freely; the incidence of incisional herniae appears very low; and tension sutures with their many disadvantages are unnecessary.

I recommend this technique of closing wounds to all surgeons.

H G STURZAKER

Guy's Hospital,

Guy's Host
London

Jenkins, T P N, British fournal of Surgery, 1976, 63,

SIR,-I think you could have omitted the question mark from the title of your otherwise admirable leading article on burst abdomen (26 February, p 534).

There are as many ways of closing the abdomen as there are surgeons doing it, but the incidence of such a calamity as you mention and the related complication, incisional hernia, can be reduced below the alarming levels you quote.

Unabsorbable material, even monofilament polyethylene, is liable to leave a foreign body sinus in a percentage of infected cases. Any suture material should, as you say, retain its tensile strength a bit more than long enough for the relatively avascular linea alba or rectus sheath to heal strongly and should then entirely disappear. In the 10 years since polyglycolic acid sutures have been available, allowing easy and accurate apposition of the layers of the abdominal wall (the relatively avascular layer being protected with a lattice stitch for added security) the incidence of burst abdomen, incisional hernia, and wound sinus has, if not "virtually disappeared," at least been considerably reduced in this unit.

It is these iatrogenic complications which increase morbidity and mortality and consume time and money. With your encouragement we shall continue to strive to make them all real rarities.

Cheltenham General Hospital,

Peter BorehaM

Cheltenham, Glos

\section{Training the trainers}

SIR,-Recent $B M \mathcal{F}$ articles and correspondence show the deep divisions between those who enthusiastically espouse quite sophisticated courses and methods designed to develop training skills in general practitioners and those who are sincerely sceptical-usually as a result of some personal experience. Between the holders of these polar beliefs and attitudes lie many trainers whose discriminatory skill has enabled them not just to sift the educational wheat from the chaff but also to recognise that learning to become a general practitioner depends on a judicious blend of different techniques-some very old, some recent. Direct instruction (you should see the secretary about these forms), apprenticeship (you've watched me, now try it yourself), selfteaching (you'll learn that best by seeing patients, or reading, or listening to cassettes), shared problem-solving (what is your own opinion about this problem?), sensitivity training (making contact in a group with your own feelings and relationships), and other instruments can all contribute to trainee learning provided the trainer feels at ease with them and is conscious of when he should use them.

But to deluge potential or actual trainers with jargon-loaded educational theory the application of which to general practice training has been inadequately tested is both discreditable and dangerous. Overdosage with such teaching leads either to a false misunderstood mystique or to near-total rejection of the need to learn to train. As a medical teacher I am just as dismayed by the wrong but sometimes understandable resort to nostalgic empiricism (you can only learn by apprenticetype experience like we did) as I am by the evasive resort to reflected questions (why did you respond to my question about how you felt about this patient by asking me why I asked you that question?) or by the arid insistence on excessive or unevaluatable objectives (the trainee shall be able to keep records - records of what, in what form, and how much ?). To perpetuate these opposing standpoints by intransigent statements serves neither trainee nor trainer well.

Until accurate, valid, credible, and useful tests of training skills are available-and in my view we are a long way from such consummation-surely the best way forward is a continued reliance mainly on traditional on-thejob learning by trainees, with day release courses for some theoretical teaching but accompanied by a programme of evaluation of different techniques under more controlled conditions than has obtained hitherto. The diversity of training policies and practices must now be quite sufficient to allow measurement of trainee learning to tell us how effective various patterns are. Such experiments of opportunity are badly needed if the way ahead is to become respectable and acceptable.

I M RICHARDSON

Department of General Practice,

University of Aberdeen

\section{Metabolic and cardiotoxic effects of} salbutamol

SIR,-We have read with interest the recent article relating to the metabolic effects of salbutamol by $\mathrm{Mr} \mathrm{A}$ Neville and others (12 February, $p$ 413) and the comparison of salbutamol with aminophylline in severe asthma by Professor D Femi-Pearse and others (19 February, p 491).

Studies in stable asthmatics and in normal subjects have demonstrated metabolic changes, including a rise in plasma nonesterified fatty acid (NEFA) concentration following salbutamol infusion. However, in a study of 63 asthmatic patients admitted with an acute attack pretreatment NEFA concentration was greatly elevated, and no further rise was measured during a subsequent salbutamol infusion. ${ }^{1}$ The infusion $(10 \mathrm{\mu g} / \mathrm{min})$ was associated with an increase in plasma glucose and insulin and a fall in plasma potassium concentrations similar to those in stable asthmatics and normal subjects. ${ }^{2} 3$ Thus the stress of acute asthma may in itself cause an increase in NEFA concentration and the response to salbutamol may not necessarily be as hazardous as claimed.

Professor Femi-Pearse and his colleagues state that aminophylline may be cardiotoxic and responsible for sudden death if administered rapidly. Intravenous salbutamol $(200 \mathrm{\mu g})$ given in one minute caused a rise in pulse rate of 13.4 beats/min when measured five minutes later. They do not report the pulse rate before administration, nor did they measure the pulse rate at a shorter interval after administration. Fitchett et $a l^{4}$ have 